\title{
Using Multisensory Learning Approach for EFL Letter Recognition of Preschool Dyslexic
} Children

\author{
by \\ Aml Gameel Aly El-Morsy*
}

\begin{abstract}
The current study was conducted to determine the effectiveness of a suggested Multisensory phonics program in developing EL letter recognition for preschool dyslexic children, combined with several instructional procedures, to improve the EL letter recognition skills of preschool dyslexic children. A total of 10 preschool dyslexic children participated in the study that involved one group experimental design. The experiment lasted for six weeks. The pre/posttests were administered to assess the participants' EL letter recognition skills. The results showed that the suggested Multisensory learning approach program was effective in developing preschool dyslexic children's EL letter recognition

Keywords:

Multisensory Learning Approach (MLA), EFL letter recognition, preschool dyslexic children.
\end{abstract}

*Curriculum \& Instruction (TEFL) dep.Hurghada Faculty of education South Valley University 
دراسة بغوان إستخدام مدخل التعلم القائم على الحواس المتعدة للتعرف على الحروف

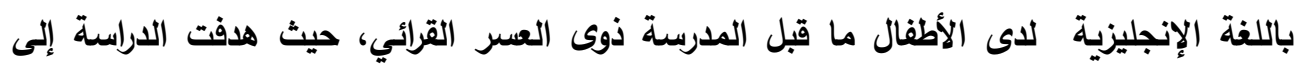

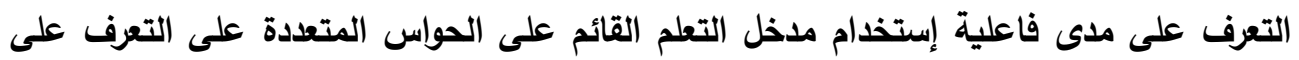

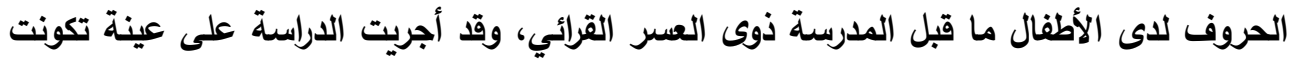

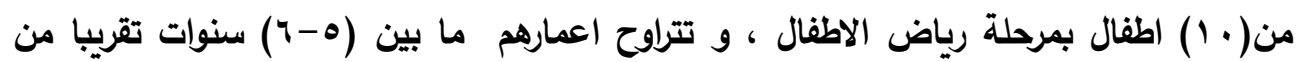

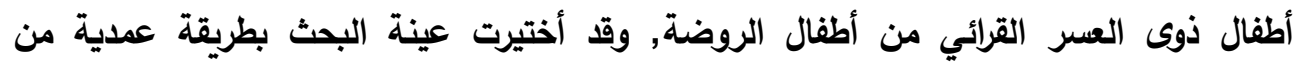

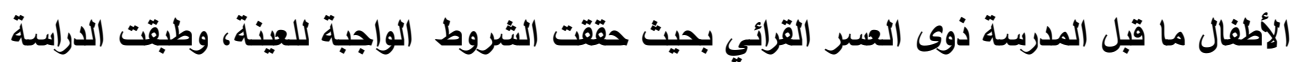

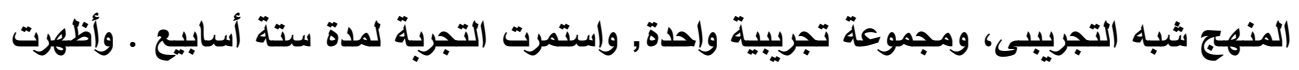

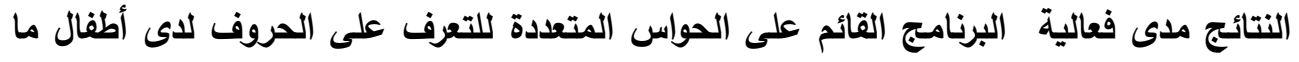
قبل المدرسة ذوى العر القرائي.

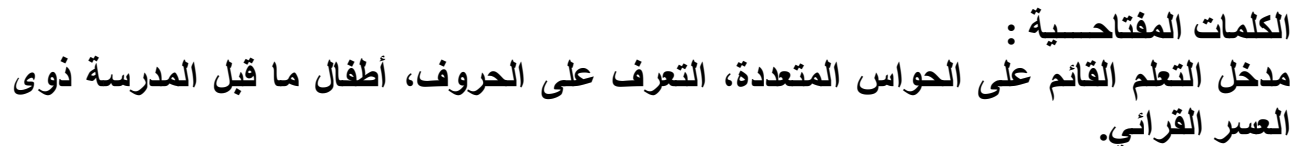




\section{Introduction}

One of the useful building blocks for successful EFL literacy instruction is to give explicit instruction in phonics. EFL learners need to build automaticity in bottom-up skills such as phonics to decode and spell words. The English language has 26 letters representing 44 sounds with more than 500 ways to spell them, so even native speakers of English receive instruction to handle decoding English (Campbell et al., 2014).

Children need to use many sensory modalities to explore their environment multisensory approaches to reading are based on the idea that many students learn best when material is presented in several different modalities. Children should be encouraged to move around, touch, smell and taste objects, because it has been found that the more senses involved in investigating an object, the more likely they are to develop ways to remember the objects or recall their experiences.

As Phipps (2011) pointed out, synthetic phonics is a fast track multisensory approach to teach reading accuracy. It starts with the smallest units of speech-sounds and building up to bigger units by blending the small ones together. The basic skills in synthetic phonics are: learning the letter sound, letter formation, and blending and segmenting skills. Synthetic phonics has been found to be a fast and effective method for teaching reading accuracy (Malmeer \& Araghi, 2013). As it is more fun and makes learners more engaged in language learning, learners are encouraged to read and write the letters in the air, on their hands, and on their partners' backs.

Having the ability to match letters and sounds helps children to develop their EFL letter recognition and spelling patterns. Students with dyslexia have trouble with language skills involving speech sound (phonological) and print (orthographic) processing and in building pathways that connect speech with print. The awareness of a new method, in this case, the multisensory phonics method, evokes a series of responses in the preschool dyslexic children towards their learning.

\subsection{Context of the Problem}

The current study addressed the question of whether or not preschool dyslexic children benefit from a multisensory phonics program on the development of their EFL letter recognition. The problem of the current study was derived from the following resources:

a. Personal observation of the researcher that showed that preschool dyslexic children have difficulty in discriminating English phonemes. 


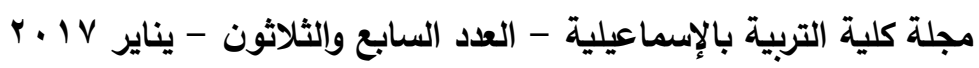

They have weaknesses in phonological skills and this affects their ability to decode with efficiency.

b. A pilot study conducted by the researcher which was an oral blending and segmenting assessment. Twenty preschool dyslexic children, enrolled in the kindergarten, participated in the study. The pilot study has revealed the following findings: (a) EFL preschool dyslexic children have difficulty in distinguishing between sounds in English, (b) sound/letter correspondence is not correct.

\subsection{Statement of the problem}

Preschool dyslexic children often have EFL letter recognition problem. So, the researcher suggested the application of the Multisensory Learning Approach (MLA) to solve the target preschool dyslexic children's EFL letter recognition problem.

\subsection{Study Questions}

The current study attempted to provide answers to the following questions:

a) What are the EFL letter recognition skills necessary for preschool dyslexic children?

b) What are the theoretical bases of the multisensory learning approach program for EFL letter recognition ?

c) What is the effect of using a multisensory learning approach for EFL letter recognition of preschool dyslexic children?

\subsection{Study hypotheses}

$H_{1}$ There are statistically significant differences between the mean scores of the pre/posttest of EFL letter recognition skills test in favor of the post testing.

$H_{2}$ There are statistically significant differences between the mean scores of the pre/ posttest on the EFL letter recognition skills in favour of the posttest.

\subsection{Study Significance}

The current study is thought to be important for the following:

a. Enhancing preschool dyslexic children's EFL letter recognition .

b. Proposing a suitable instructional method to aid the preschool dyslexic children in EFL letter recognition .

c. Assisting teachers in using different strategies based on the MLA.

\subsection{Study Aims}

It aims at the following: 
a. Identifying EFL letter recognition skills needed for the preschool dyslexic children.

b. Identifying the effect of the proposed program based on multisensory learning approach on EFL letter recognition of preschool dyslexic children.

\subsection{Study Delimitations}

This study was delimited to the following:

a. Some EFL letter recognition skills: phonological awareness, phonemic awareness, and the alphabetic principle.

b. A sample of $\mathbf{1 0}$ preschool dyslexic children in kindergarten.

\subsection{Definition of Terms}

1.8.1. Multisensory Learning Approach

It means learning via many senses in which teachers should employ human senses (sight, hearing, smell, taste and touch) as possible in the classroom activities (Nijakowska, 2010).

1.8.2. EFL Letter recognition is the ability to recognize and name the letters of the alphabet. It includes recognizing and recalling the shapes of letters, identifying lower and upper case letters, and recognizing letters in isolation and within printed words even when they appear in different fonts and sizes (NZTE, 2017).

1.8.3. Dyslexia

"A specific reading disability due to a defect in the brain's processing of graphic symbols. Dyslexia is a learning disability that alters the way brain processes written material" (Medicine Net, 2011).

\section{Review of Literature}

\subsection{EFL Letter recognition}

Letter knowledge is a basic cornerstone for preschool dyslexic children' literacy. They must be able to identify, discriminate similar looking letters, and name each letter in the alphabet in order to make meaningful associations between letter symbols and their corresponding sound representations (Pinto et al., 2015). Knowledge of the alphabetic principle refers to a realization that, in alphabetic orthographies, spoken words are comprised of phonemes and the phonemes are represented in text as letters (Gunning, 2009).

The development of effective intervention methods for improving EFL letter recognition for preschool dyslexic children' reading skills has to focus on several aspects of such instruction.

2.1.1 Importance of EFL Letter recognition 


$$
\text { مجلة كلية التربية بالإسماعيلية - العدد السابع والثلاثون - يناير P V P }
$$

Recent research indicates that reading depends first and foremost on visual EFL letter recognition. Studies have shown that the knowledge of letter names is the best predictor of success in reading. McCormick and Zutell (2011) stressed that when children struggle with reading it promotes displeasure, indifference and avoidance for reading. They emphasized that children who fall behind in reading early in their schooling will continue to lag behind their classmates. This is because children who read will tend to read more, but children who struggle with reading tend to read less and their reading skills do not advance (McCormick \& Zutell, 2011).

Bara et al., (2014) recommend that students should receive instruction that develops their phonological and phonemic awareness. They feel that phonological awareness and phonemic awareness are not enough for students to develop their phonological decoding skills. Their study showed a more effective foundation for students is to receive training in phonological awareness and letter knowledge when learning how to read. McCormick and Zutell (2011) confirmed that students in order to become successful readers, they need to acquire phonological awareness, phonemic awareness, and the alphabetic principle.

\subsubsection{Foundations of EFL Letter recognition}

\section{a. Phonological Awareness}

According to Caldwell and Leslie (2013) reported that phonological awareness is the understanding that the English language contains units of sounds that vary in size. Some of the units have many sounds that are in a syllable and others have just one sound. There are three levels of phonological awareness that are important for reading development: the syllable, onset-rime, and phoneme. Current research revealed that children's phonological awareness should be developed before children start school. Caldwell and Leslie (2013) agreed that phonological awareness has a broader focus which includes identifying and manipulating larger parts of spoken language, such as words, syllables, rimes, phonemes, and awareness of the other aspects of sounds, such as rhyming, alliteration, and intonation.

b. Phonemic Awareness

The ability to manipulate phonemes in spoken words such as syllables and rhyming words is an essential characteristic of phonemic awareness (McCarthy, 2008). An understanding of phonics enables learners to use alphabetic code breaking skills to decode written words (Zimmerman et al., 2008). In learning to read words, students need to 
decode by transforming graphemes into a blend of phonemes (Ukrainetz, 2009).

According to Carlson et al. (2013), phonemic awareness refers to the understanding of various ways oral language can be broken down into smaller components and manipulated with an understanding of how language is constructed and used. Phonemic awareness is the insight that spoken words are made up of a sequence of separable sounds. It also involves the understanding that spoken words are made of separate sounds that can be analyzed, manipulated, and represented in print. To build phonemic awareness, children need to hear words as a sequence of sounds and then link those sounds to letters (McCormick \& Zutell, 2011).

Findings from research on phonemic awareness recommend that phonemic awareness can be taught and learned. As children learn to read, their phonemic awareness continues to develop. It is important for students to continually develop their phonemic awareness, so they have an easier time learning how to read. Recent studies found that the continual development of phonemic awareness early in school was critical to children's success in learning to read (Graves et al., 2011).

c. The Alphabetic Principle

The alphabetic principle is the insight that spoken words can be written by letters (McCormick \& Zutell, 2011). In order for children to understand the alphabetic principle, they must understand the concept that letters represent sounds (Gunning, 2010). EFL letter recognition is one of the key tasks of learning to read. This task is difficult because the English language is not consistent with its one-to-one relationships between letters and sounds. This is important because students need to recognize letters and their distinguishing features in order to effectively work with print (McCormick \& Zutell, 2011).

Letter names provide clues to the sounds associated with the letter, because if a student forgets the sound that a letter represents, the letter's name may help the student remember. As a result, when students learn letter names, they are also learning letter sounds (Gunning, 2010). McCormick and Zutell (2011) cautioned that children need to understand the connections between 44 phonemes (sounds) of spoken English and the 26 letters that they represent. This is why that a child who can figure out which sounds are represented by letters has a powerful tool for reading words. On the other hand, a child who cannot figure out letter/sound correspondences will be unable to decode a word that he has not previously read (McCormick \& Zutell, 2011). 


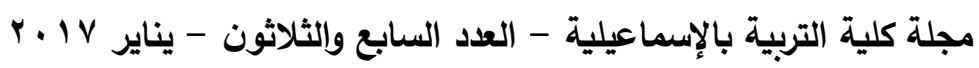

d. Identifying phonemes: The child can identify the first sound in the word cat or the last sound in the word $d o g$ or identify a common phoneme in a group of words like bit, sat and wet, and then they have demonstrated this skill (Elliott\& Grigorenko, 2014).

e. Isolating phonemes

This skill involves isolating where in a word a specific sound resides. For example, in the word 'bug' where is the /g/ sound locatedat the beginning, middle or end? The most difficulty and last kind of isolation to be learned is identifying phonemes in the middle of words, this exercise is done orally, not using letters on paper and is harder for young children than it sounds (Bates, 2017).

\subsection{The Benefits of Multisensory Learning Approach for} EFL Letter Recognition

According to Bara et al. (2014) the effects of adding visuo-haptic and haptic exploration of letters in a reading intervention program for preschool dyslexic children designed to develop phonemic awareness and EFL letter recognition and letter-sound recognition.

The results of the study showed that, incorporating the visuo-haptic and haptic exploration increases the positive effects of the intervention on understanding and use of the alphabetic principle for children and their reading level.

At present, there are several multisensory instruction techniques that use a mixture of visual, auditory, tactile-kinesthetic approaches. Earlier research showed that lip and hand kinesthetic elements seem to be the essential link between the visual cue and the various associations. Children should see a letter, trace it, and then say the letter name and the corresponding sound connection in order to learn their letters and corresponding sounds (Shams\& Seitz, 2008).

Flynn (2005) noted that the Orton Method stresses the importance of the senses of seeing, hearing and feeling. She explains that learning takes place through visual, auditory, and kinesthetic-tactile modalities. These modalities process information in a way that helps students to compensate for specific processing difficulties. Additionally, the kinesthetic-tactile modality is activated by motor activity through body muscles and speech organs which functions as the "glue that bonds the information to the brain, starting with the teaching of individual letters, the visual and auditory pathways are strengthened by the simultaneous introduction of the motor elements of speech and writing.

Students benefit because multisensory instruction establishes the association between letter units and their sounds in both directions. 
This association is developed when students see a letter and say a sound and then the teacher says a sound and students respond by naming the letter and writing it. When teachers use multisensory instruction in their classrooms, they are teaching children to link letters with the written symbols. With multisensory instruction, children also link the sound and symbol with how it feels to the letter or letters. As students learn a new letter or pattern (such as $t$ or $c h$ ), they carefully trace and then write the letters while saying the corresponding sound. During instruction, the sound may be made by the teacher, the letter name is provided by the teacher, and the letter name is provided by the student. When multisensory instruction is used in the classroom, teachers and students learn to rely on visual, auditory, kinesthetic/tactile pathways for learning instead of using a traditional method like memorizing sight words or phonetic methods (Henry, 2010).

The benefits of using multisensory learning approach on EFL letter recognition for kindergarten dyslexic students have been discussed in multiple studies. This review explained that multisensory instruction contains visual, auditory and kinesthetic/tactile components. This review also explained that learning takes place through visual, auditory, and kinesthetic/tactile modalities which can engage each student's learning style and increase children's attention to task.

\subsection{EFL Letter Recognition for Preschool Dyslexic Children}

Dyslexia is a specific language disorder of constitutional character, which is manifested by difficulties in decoding the words; caused by the insufficient phonological processing by the reader. The problems appear unpredictably considering the age and the other cognitive skills (Schneider, 2008).

Besides the difficulties of reading and spelling that are generally associated with dyslexia, Zelinkova (2009) stated that dyslexia affects four main features of the reading process. There are difficulties in recognizing language patterns that are presented orally. The phonological deficit has been the dominant cognitive explanation of dyslexia. Children with dyslexia are hindered by faulty representation of speech sounds, which leads to problems involving the precise processing of spoken words.

Assessing and improving the cognitive processing of spoken words should be an objective of every preschool stage because phonemic awareness is a prerequisite to a suite of critical skills including letter sound decoding (phonics), rapid word identification (use of site words) and fluency (Elliott \& Grigorenko, 2014). 


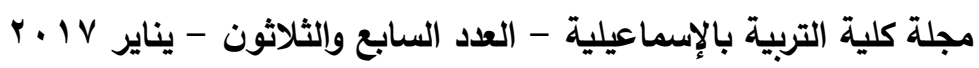

The best practice for teaching dyslexic learners is to teach them via all their senses (multisensory teaching). This means using visuals, motion, body movement, hands-on, and auditory elements in their learning. Dyslexic children draw from various regions in their brains while engaging in reading, so it stands to reason that using teaching approaches that stimulate various regions in the brain would ensure success for these learners. Dyslexic learners need to learn using an approach that simultaneously combines auditory, visual, and tactile learning strategies as multisensory learning to teach skills and concepts for preschool dyslexic children to improve EFL letter recognition skills in this study.

\section{Methodology}

The major purpose of this study is to discover whether preschool dyslexic children would improve their ability to recognize and read letters as a result of learning through their visual, kinesthetic and tactile modalities as opposed to their visual and auditory modalities alone.

\subsection{Design of the Study}

The current study is a pre/posttest quasi-experimental one. The study group was tested before conducting the treatment. During experimentation, the study group was taught using the multisensory phonics program. At the end of the treatment, participants were post tested.

\subsection{Variables of the Study}

The independent variable of this study is the multisensory phonics program while the dependent variable is represented in EFL letter recognition for preschool dyslexic children.

\subsection{Participants of the Study}

The participants of the current study were 10 preschool dyslexic children, aged between 5-6 years almost. Participants have studied multisensory phonics program. Consequently, they are supposed to master the basic EFL letter recognition skills.

\subsection{Stud y Instruments}

3.4.1. EFL Letter Recognition Skills Test

The EFL letter Recognition Skills Test was designed by the researcher to determine each participant's level of EFL letter recognition across a 
variety of test items. It was used as a pre/posttest to find out the effectiveness of the suggested multisensory program. The test consisted of questions that measured the participants' skills of EFL letter recognition (phonemic awareness: alphabet recognition; letter identification; sounds identifying and letter formation) as shown in (Appendix 1).

\subsubsection{Test Validity}

The EFL Letter Recognition Test was given to a panel of jury in the field of linguistics and TEFL to judge its validity. The jury agreed that the test properly measures the aim of using it.

3.5.1.2. Test Reliability

Test- retest method was used to determine the reliability of the test. The correlation coefficient was 0.85 which is highly reliable.

3.5.2. The Multisensory Learning Strategies Program

The program includes various activities of multisensory learning strategies to practice and consolidate the letter(s)/sound connections.

\subsubsection{Program objectives}

By the end of the program, participants were expected to:

a. Acquire MLA strategies and techniques.

b. Develop their EFL letter recognition skills (phonemic awareness: alphabet recognition; - uppercase letters; alphabet recognition lowercase letters; letter sound identification; isolating the initial phoneme and identifying final sounds in words. In order to attain these objectives, three multisensory learning strategies were specified.

3.5.2.2. The MLA program description

It is a program that teaches the basic components of the English language sounds and letters, and integrates the multisensory learning strategies for preschool dyslexic children's EFL letter recognition skills. This intervention of MLA advocates learning the phonemic awareness and alphabet recognition. The MLA program associates the visual, auditory and kinesthetic strategies. When reading, participants trace the letter as they see it and say the name of the letter and sound. The MLA activities program includes four units for improving EFL letter recognition skills of five main (phonemic awareness activities: alphabet recognition; letter identification \& formation; sounds identifying; sound production\& discrimination and letter formation) as shown in (Appendix 1).

3.5.2.3. Program validity 
The program was given to EFL specialists who approved it and suggested some modifications. Their suggestions were considered in the final version.

3.5.2.4. Program content

This program is composed of two parts for developing using multisensory learning approach on EFL letter recognition for preschool dyslexic children. The first part is a Teacher's Guide that contains three units tackling the multisensory learning strategies to improve preschool dyslexic children's EFL letter recognition skills. The program includes the following units: unit one-visual strategies; unit two-auditory strategies; unit three-tactile strategies and unit four-kinesthetic strategies. The second part is a Students' Book. This part of the program is divided into four units. The unit is devoted to help children proceed through activities that differ from one component to another and have training on discrete strategies and skills.

\subsubsection{Teaching strategies and techniques}

Multisensory learning strategies are those activities that facilitate preschool dyslexic children's ability for the EFL letter recognition. They are the scaffolds that help support dyslexic children in EFL letter recognition process. The researcher followed the proposed teaching strategies and their implication on EFL teaching/ learning using different, careful, and selected techniques aiming at developing preschool dyslexic children's ability for the EFL letter recognition components. According to these teaching strategies, each session is divided into three phases including the teaching strategies and techniques that overlapped and intertwined. The first session included the interactive and guided alphabet activities to recognize the letters of the alphabet through the use of multisensory learning strategies. The second session included the independent EFL letter recognition components, assessment and evaluate.

Below are the main MLA strategies and techniques adopted in the program:

- Visual Strategies (using the sense of sight)

* Organizing information or imagery.

* Creating art, images, pictures and video.

* Using many different colors.

- Auditory Strategies (using the sense of hearing)

* Accompanying audio music, song, speaking, chants and video.

* Singing songs.

-Tactile Strategies (using the sense of touch) 
* Drawing / Painting letters.

* Modeling materials such as clay and sculpting materials.

* Sorting letters.

* Using small materials called manipulative to represent letters.

- Kinesthetic Strategies (using body movements)

* Air writing

* Building models \& Building words with letter tiles.

* Clapping or other movements paired with activities.

* Modeling letters using children' bodies.

* Pair large movement activities, with rhythmic recall and academic competition such as quizzes and flash card.

* Learning games or other movements.

\subsubsection{Duration of the Experiment}

Duration of the program time lasted for six weeks. Thus, all the program units took twenty four sessions (twenty four hours).

3.5.2.7. Teaching- learning activities

Dyslexic learners had be involved in a variety of multisensory learning strategies and activities that were targeted to promote their EFL letter recognition components. The program introduced a variety of activities to involve the participants in pair work, group work and individual work. Examples of the MLA activities in this program were as follows: visual, auditory, tactile and kinesthetic activities while performing EFL letter recognition activities: alphabet recognition; - uppercase letters; alphabet recognition - lowercase letters; letter sound identification; isolating the initial phoneme and identifying final sounds in words)

3.5.2.8. Assessment Checklist for students

This assessment, which is particularly useful in EFL letter recognition components, gave the teacher valuable insights to monitor students' use application of the MLA strategies. Teacher used the MLA strategies with the student's assessment. In addition, the teacher needed to have a written record of observations during the children's work, which provided:

(8) A mechanism for fair and consistent feedback to the students.

(b) A way of making sure that every student was being observed in a timely fashion.

(b) Assurance of the information from observations was not forgotten over time.

3.5.2.8. Implementation of the program 


$$
\text { Pلم كلية التربية بالإسماعيلية - العدد السابع والثلاثون - يناير r. V }
$$

3.5.2.8.1. The orientation session

The aim of this session was to prepare preschool dyslexic children for the intervention. The researcher has conducted the following steps:

- Explaining the importance and the aims of the suggested multisensory phonics program.

- Identifying what's meant by multisensory phonics and EFL letter recognition .

- Clarifying how to associate sounds with letters.

- Training participants to use their senses during the application of the suggested multisensory program.

\subsection{Experimentation}

The participants of the study were trained to master the following skills: phonemic awareness: alphabet recognition; - uppercase letters; alphabet recognition - lowercase letters; letter sound identification; isolating the initial phoneme and identifying final sounds in words, sound production, sound discrimination and letter formation. Participants were also taught many games which had made learning enjoyable. The training was expected to cause a change in their EFL letter recognition skills. The participants were trained to use the following phonemic awareness activities:

Sound production

During each instructional session in which a new letter was introduced, the preschool dyslexic children were asked to repeat a sound articulated by the researcher. After repeating the articulation of the sound, participants were asked to focus on specific physical aspects of sound generation, such as which parts of their mouth, lips, tongue, and teeth are helping to make that sound. Participants were also asked to focus on how the movement of air through their noses and mouths as well as vocal cord movement assist in the generation of specific sounds.

\section{$>\quad$ Sound /Letter discrimination}

During lessons in which a new letter/sound was introduced, participants were presented with mixed pictures, images, pictures and video. Some of the cards contained pictures started with the target sound and some of the cards did not. They had to discriminate between the target sound and the non-target ones. When they disagreed on a given card, they were guided to use slow articulation in order to confirm the appropriate identification of target sounds.

$>\quad$ Sound Identification

During review lessons, preschool dyslexic children played various games accompanying audio music, singing songs, instruments, 
speaking, chants and video, which required them to categorize picture cards according to the appropriate letter and sorting letters. The groups of letters used in these review games were based on linguistic categorization. For example, if the letters $c / k, r, p, m, n$ were being reviewed, pictures containing these letters were placed on the white board using the power point program. Preschool dyslexic children were given 3-4 picture cards each that contained the initial sound of one of the letters being reviewed. After placing the picture card under a given letter, participants were prompted to articulate the first sound of the picture.

$>$ Letter identification and formation

Letters were introduced according to the schedule through MLA activities as air writing, building models \& building words with letter tiles, using many different colors and modeling letters using children' bodies. Participants were provided letter cards (capital and lower case), which they traced with their fingers on the air or on their peers' back in order to provide tactile experience with letter formation. Participants name the letter as they were tracing.

$>$ Writing

Participants were provided with their own journals to briefly practice letter formation skills. They were also given the opportunity to write letters through drawing / painting letters, air writing, building models and building words with letter tiles. The inclusion of a letter formation component served to reinforce tactile encoding as well as providing initial experience with writing letters.

\section{Results}

SPSS (Statistical Package for the Social Sciences, version16) was used to analyze the participants' scores on the pre/posttests. Results are shown in light of the study hypotheses and questions.

\subsection{Results Related to the First Hypothesis of the Study}

Hypothesis One:

There are statistically significant differences between the mean scores of the pre/posttest of EFL letter recognition skills test in favor of the post testing. The $T$-value of the difference between the pre/posttest is shown in Table 1. 
مجلة كلية التربية بالإسماعيلية - العدد السابع والثلاثون - يناير IV P P P

Table 1The mean scores of the pre/posttest of EFL letter recognition skills test

\begin{tabular}{|c|c|c|c|c|c|c|c|}
\hline EFL & $\begin{array}{c}\text { Type of } \\
\text { test }\end{array}$ & $\mathbf{N}$ & Mean & $\begin{array}{c}\text { Std. } \\
\text { Deviation }\end{array}$ & $\begin{array}{c}\text { T- } \\
\text { value }\end{array}$ & df & Sig. \\
\hline Letter & pretest & 10 & 11.90 & 1.411 & \multirow[t]{2}{*}{38.801} & \multirow[t]{2}{*}{39} & \multirow[t]{2}{*}{ Significant } \\
\hline $\begin{array}{c}\text { recognition } \\
\text { test }\end{array}$ & posttest & 10 & 24.75 & 1.391 & & & \\
\hline
\end{tabular}

As Table 1. shows, the mean score of the overall EFL letter recognition pretest is $\mathbf{1 1 . 9 0}$ while the mean score of the posttest is 24.75 , there existed a significant difference between the mean score of the pre/posttest of the study group regarding the overall EFL letter recognition in favour of the posttest $(T=38.80, p>0.01)$. Thus, the first hypothesis is accepted. This table is represented graphically in the following figure:

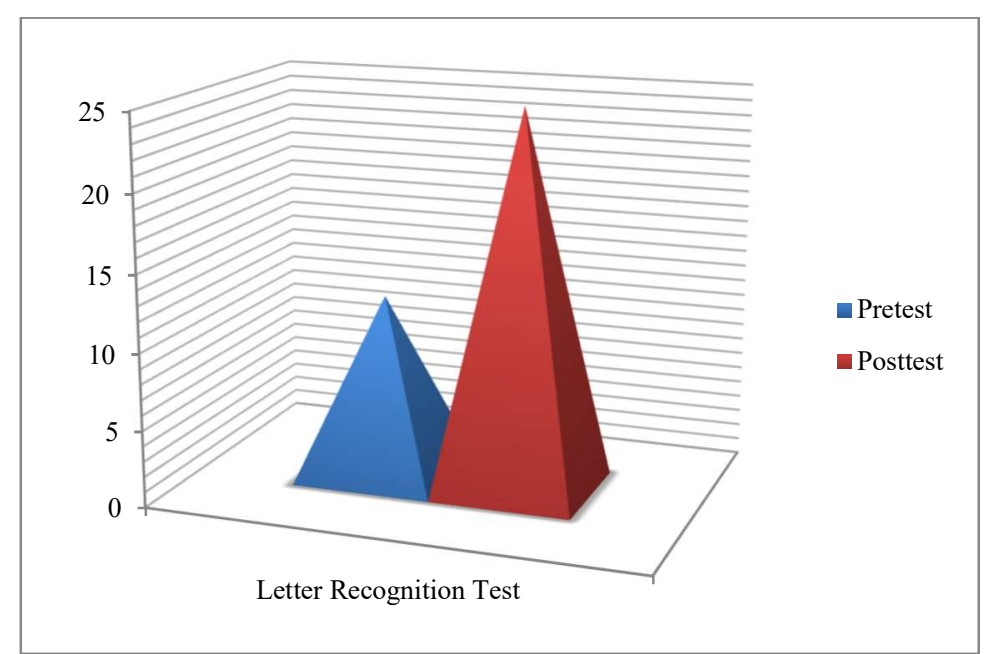

Figure1. Results of the overall EFL Letter Recognition Test

Hypothesis two: There are statistically significant differences between the mean scores of the pre/ posttest on the EFL letter recognition skills in favour of the posttest. In order to investigate this hypothesis, T-test was used to compare the mean score of the study group on both the pre/posttest on the EFL letter recognition skills. Table 2 showed the Ttest value of the difference between the pre/posttest. The significance of differences between the mean scores of the study group on the pre/posttest the EFL letter recognition skills are shown in Table 2. 
The pre/posttest on the EFL letter recognition skills.

\begin{tabular}{|c|c|c|c|c|c|c|c|}
\hline Skills & $\begin{array}{c}\text { Type of } \\
\text { test }\end{array}$ & $\mathbf{N}$ & $\begin{array}{c}\text { Mea } \\
\mathbf{n}\end{array}$ & $\begin{array}{c}\text { Std. } \\
\text { Deviatio } \\
n\end{array}$ & $\begin{array}{c}\text { T- } \\
\text { value }\end{array}$ & df & Sig. \\
\hline \multirow{2}{*}{$\begin{array}{c}\text { Alphabet } \\
\text { recognitio } \\
\text { n }\end{array}$} & pretest & $\begin{array}{l}1 \\
0\end{array}$ & 2.85 & .662 & \multirow[t]{2}{*}{$\begin{array}{c}12.60 \\
9\end{array}$} & \multirow[t]{2}{*}{$\begin{array}{l}3 \\
9\end{array}$} & \multirow{2}{*}{$\begin{array}{l}\text { Signific } \\
\text { ant }\end{array}$} \\
\hline & $\begin{array}{c}\text { posttes } \\
t\end{array}$ & $\begin{array}{l}1 \\
\mathbf{0}\end{array}$ & 5.92 & 1.309 & & & \\
\hline \multirow{2}{*}{$\begin{array}{c}\text { Letter } \\
\text { identificat } \\
\text { ion }\end{array}$} & pretest & $\begin{array}{l}1 \\
\mathbf{0}\end{array}$ & 3.10 & .709 & \multirow[t]{2}{*}{$\begin{array}{c}18.53 \\
5\end{array}$} & \multirow[t]{2}{*}{$\begin{array}{l}3 \\
9\end{array}$} & \multirow{2}{*}{$\begin{array}{l}\text { Signific } \\
\text { ant }\end{array}$} \\
\hline & $\begin{array}{c}\text { posttes } \\
t\end{array}$ & $\begin{array}{l}1 \\
0\end{array}$ & 6.28 & .847 & & & \\
\hline \multirow{2}{*}{$\begin{array}{c}\text { Sounds } \\
\text { identifyin } \\
\mathrm{g}\end{array}$} & pretest & $\begin{array}{l}1 \\
0\end{array}$ & 3.02 & .768 & \multirow[t]{2}{*}{$\begin{array}{c}16.43 \\
1\end{array}$} & \multirow[t]{2}{*}{$\begin{array}{l}3 \\
9\end{array}$} & \multirow{2}{*}{$\begin{array}{l}\text { Signific } \\
\text { ant }\end{array}$} \\
\hline & $\begin{array}{c}\text { posttes } \\
t\end{array}$ & $\begin{array}{l}1 \\
\mathbf{0}\end{array}$ & 6.30 & .883 & & & \\
\hline \multirow[t]{2}{*}{$\begin{array}{c}\text { Letter } \\
\text { formation }\end{array}$} & pretest & $\begin{array}{l}1 \\
\mathbf{0}\end{array}$ & 2.85 & .662 & \multirow[t]{2}{*}{$\begin{array}{c}19.62 \\
6\end{array}$} & \multirow[t]{2}{*}{$\begin{array}{l}3 \\
9\end{array}$} & \multirow{2}{*}{$\begin{array}{l}\text { Signific } \\
\text { ant }\end{array}$} \\
\hline & $\begin{array}{c}\text { Posttes } \\
t\end{array}$ & $\begin{array}{l}1 \\
\mathbf{0}\end{array}$ & 6.18 & .903 & & & \\
\hline \multirow{2}{*}{$\begin{array}{c}\text { EFL } \\
\text { Letter } \\
\text { recognitio } \\
\text { n } \\
\text { (phonemi } \\
\text { c } \\
\text { awareness } \\
\text { ) }\end{array}$} & pretest & $\begin{array}{l}1 \\
\mathbf{0}\end{array}$ & 11.90 & 1.411 & \multirow[t]{2}{*}{$\begin{array}{c}38.80 \\
1\end{array}$} & \multirow[t]{2}{*}{$\begin{array}{l}3 \\
9\end{array}$} & \multirow{2}{*}{$\begin{array}{l}\text { Signific } \\
\text { ant }\end{array}$} \\
\hline & $\begin{array}{c}\text { posttes } \\
t\end{array}$ & $\begin{array}{l}1 \\
\mathbf{0}\end{array}$ & 24.75 & 1.391 & & & \\
\hline
\end{tabular}

As Table 2 shows, there existed a significant difference between the mean score of the pre/posttest in favour of the posttest $(T=38.801$, $p$ $>0.01)$. Thus, the second hypothesis is accepted. To determine whether the multisensory phonics program is educationally and practically effective in improving EFL letter recognition skills for preschool dyslexic children, the effect size was calculated using $\eta 2$. $\eta 2=t 2 /(t 2+$ df) where ( $T$ ) is the ( $T$ ) value of the overall sum and (df) is the degrees of freedom. The effect size was $(\% 90)$ which is higher than the large effect size value $(\% 15)$. This reflects that the multisensory phonics program is effective in developing EFL letter recognition skills for preschool dyslexic children. The previous table is represented 


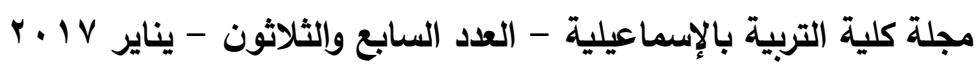

graphically in the following Figure 2. Results of the EFL letter recognition skills.

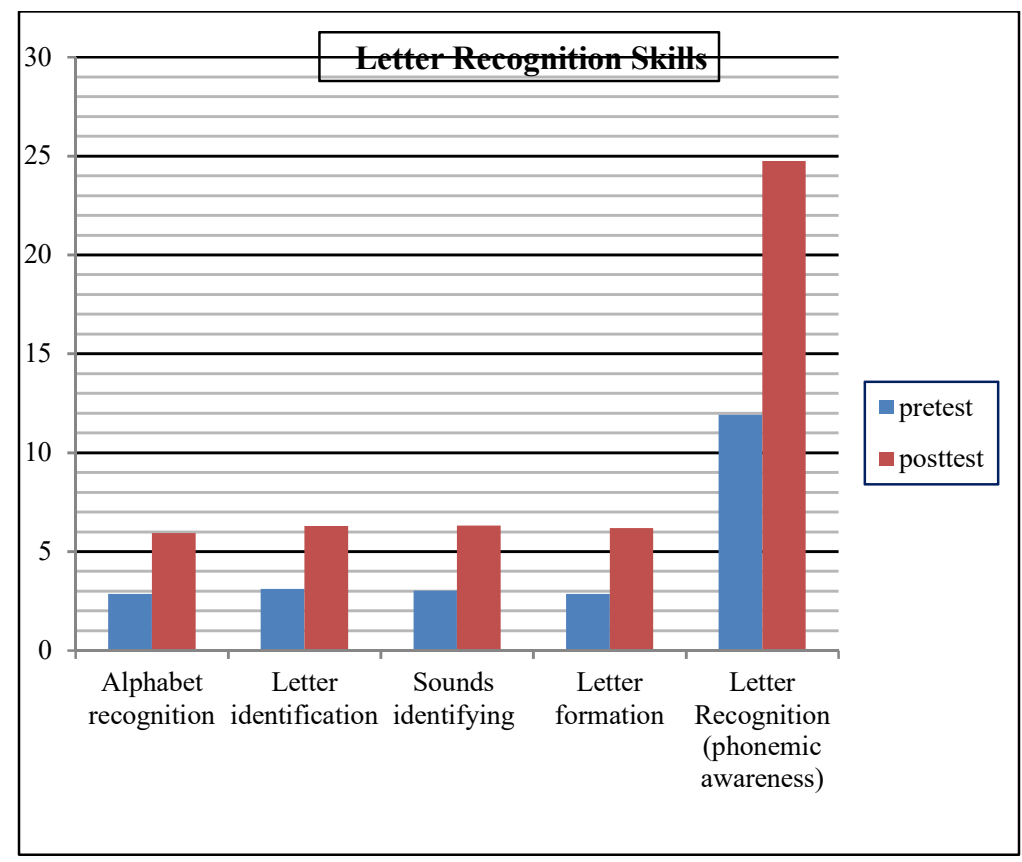

Figure 2. Results of the EFL letter recognition skills

\section{Discussion}

Consistent with other research findings involving EFL learners, results of this study demonstrated that the suggested multisensory phonics program is an effective means of improving EFL letter recognition skills, some of the foundational skills for their reading, for preschool dyslexic children. The multisensory phonics program appeared to have a significant impact. On measuring EFL letter recognition skills (phonemic awareness: alphabet recognition; letter identification; sounds identifying and letter formation), there is a strong empirical evidence suggesting that multisensory phonics instruction contributes to the development of participants' EFL letter recognition skills. The preschool dyslexic children who received multisensory phonics instruction significantly and consistently performed on measures of letter decoding and letter formation skills. These results indicate that multisensory phonics is an effective means of preschool 
dyslexic children learning how to read letters/sounds accurately during their learning experience. These findings might be due to the following:

1) The nature of the multisensory phonics program which includes supplementary letter formation activities focused on the generation of alphabet recognition; letter identification; sounds identifying and letter formation. These activities might have helped preschool dyslexic children acquire EFL letter recognition skills.

2) The multisensory phonics program provided preschool dyslexic children the skills needed for generating alphabet recognition; letter identification; sounds identifying and letter formation thus developed EFL letter recognition through enhancement phonemic awareness which led for improving EFL letter recognition skills for preschool dyslexic children's abilities.

3) The multisensory phonics program also provided preschool dyslexic children with the skills needed for combining identifying phonemes; sound/letter discrimination; letter identification and formation to discriminate and form letters. In addition, it developed their awareness of phoneme patterns which reoccur in letters and how to isolate and identify phonemes the onset.

4) Phonemic knowledge, a key instructional component of the multisensory phonics program, contributed to provide preschool dyslexic children with a visual referent form which facilitated the manipulation of individual's sounds and letters.

5) Awareness of preschool dyslexic children's phonemes and ways to form letter patterns with phonemes was emphasized in the suggested program. The preschool dyslexic children became aware of the individual sounds and letter. They recognized and connect letters with the initial consonant sounds of a word onset. Then, they became aware of the beginning/ending consonant sounds in the word.

6) The suggested program concentrated on developing the preschool dyslexic children's ability to discriminate the individual phonemes in spoken words. Besides, the ability to form individual phonemes into whole spoken/ written letters; it was largely attributed to improve EFL letter recognition for preschool dyslexic children.

7) The attractive nature of the suggested program as it trained the participants through interesting MLA activities.

8) The cooperative work created an enthusiastic environment that encouraged participants to be active and help each preschool dyslexic child with the MLA activities program. 
مجلة كلية التربية بالإسماعيلية - العدد السابع والثلاثون - يناير PV r P

Conclusion

The purpose of the present study was to investigate the degree to which preschool dyslexic children benefit from a multisensory phonics program in developing EFL letter recognition skills. The program was applied to a sample of 10 preschool dyslexic children. Findings showed that the multisensory phonics program was effective in developing the participants' EFL letter recognition skills. This study confirmed what has been demonstrated by others (Bara et al., 2014; Elliott \& Grigorenko, 2014; Flynn, 2005; Henry, 2010; Schneider, 2008; Shams\& Seitz, 2008; Zelinkova, 2009) that using multisensory phonics programs is an effective means of developing EFL letter recognition skills of preschool dyslexic children. Moreover, the current study proved the effectiveness of the multi-sensory learning approach in developing EFL letter recognition for preschool dyslexic children's phonics skills.

\section{Recommendations for Further Research}

Based on the results of the current study, the following recommendations are stated:

1) Multisensory learning approach should be emphasized in teaching and learning different features of the English language. It includes the use of various activities directed to the students' senses (gates of knowledge). It makes learning easy for them to absorb knowledge and develop literacy skills.

2) Future research is needed to determine if other programs are as effective as the multisensory phonics program in helping preschool dyslexic children's skills. They acquire some of the key foundation skills necessary for their reading success.

3) Multisensory phonics programs are also needed to be used with preparatory and secondary stage students. Multisensory phonics is an engaging and developmentally appropriate program that is relevant at all stages. 


\section{References}

2. Bara, F., Gentaz, E., Cole, P., \& Sprenger-Charolles, L. (2014). The visuo-haptic and haptic exploration of letters increases the kindergarten-children's understanding of the alphabetic principle. Cognitive Development, 19(3), 433-449. Retrieved from http://seach.ebscohost.com/login.aspx/direct=true\&db=eric\& $A N=E J 73$ H53

3. Bates, M. (2017). Dyslexia Reading Well. Retrieved from http://www.dyslexia-reading-well.com/phonemic-awareness.html

4. Caldwell, J., \& Leslie, L. (2013). Intervention strategies to follow informal reading inventor assessment, (3rd Ed.). Boston, MA: Pearson.

5. Campbell, S., Torr, J., \& Cologon, K. (2014). Pre-packaging Preschool Literacy: what drives early childhood teachers to use commercially produced phonics programs in prior to school settings. Contemporary Issues in Early Childhood, 15(1), 40. Retrieved from http://dx.doi.org/10.2304/ciec.2014.15.1.40

6. Carlson, E., Jenkins, F., Li, T., \& Brownell, M. (2013). The Interactions of Vocabulary, Phonemic Awareness, Decoding, and Reading Comprehension. The Journal of Educational Research, 106(2), 120-131. Retrieved

from http://dx.doi.org/10.1080/00220671.2012.687791

7. Clay, M., (2013). An observation survey of early literacy achievement, Hei nemann, Portsmouth, NH. Elliott,J.\& Grigorenko, E. (2014). The Dyslexia Debate. Retrieved from http://www.dyslexiareading-well.com/phonemic-awareness.html

8. Clay, M., (2013). An observation survey of early literacy achievement. Portsmouth, NH: Heinemann.

9. Good, J. E., Lance, D. M., \& Rainey, J. (2014). The Effects of Morphological Awareness Training on Reading, Spelling, and Vocabulary Skills. Communication Disorders Quarterly, 36(3), 142-151. Retrieved from http://dx.doi.org/10.1177/1525740114548917

10. Graves, M., Juel, C., Graves, B., \& Dewitz, P. (2011). Teaching reading in the 21st century, motivating all learners. Boston, MA Pearson Education.

11. Gunning, T. (2009). A Step-by-Step Program for Developing Higher Level Skills in Struggling Readers Building Struggling Students' Higher Level Literacy: Practical Ideas, Powerful Solutions (pp. 163-197): International Reading Association.

12. Gunning, T. (2010). In Ramos A. (Ed.), Creating literacy instruction for all students (Seventh Edition Ed.). Boston, MA: Pearson. 


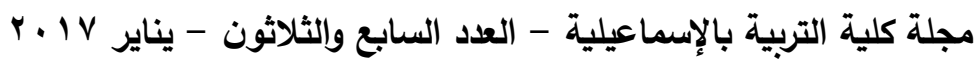

13. Henry, M (2000). Just the facts...multisensory teaching. Baltimore MD: The International Dyslexia Association. Retrieved from http://wwwinterdys.org

14. Henry, M (2010). Just the facts multisensory teaching. Baltimore MD.

15. International Dyslexia Association. Retrieved from http://wwwinterdys.org

16. Lai, S. A., George Benjamin, R., Schwanenflugel, P. J., \& Kuhn, M. R. (2014). The Longitudinal Relationship between Reading Fluency and Reading Comprehension Skills in Second-Grade Children. Reading \& Writing Quarterly, 30(2), 116-138. Retrieved from http://dx.doi.org/10.1080/10573569.2013.789785

17. Malmeer, E., \& Araghi, S. M. (2013). The Impact of Extensive Reading Programs on the Pronunciation Accuracy of EFL Learners at Basic Levels. TPLS, 3(8). Retrieved from http://dx.doi.org/10.4304/tpls.3.8.1434-1439

18. Malmeer, E., \& Araghi, S. M. (2013). The Impact of Extensive Reading Programs on the Pronunciation Accuracy of EFL Learners at Basic Levels. TPLS, 3(8). Retrieved from http://dx.doi.org/10.4304/tpls.3.8.1434-1439

19. McCarthy, P. A. (2008). Using Sound Boxes Systematically to Develop Phonemic Awareness. The Reading Teacher, 62(4), 346-349. Retrieved from http://dx.doi.org/10.1598/RT.62.4.7

20. McCarthy, P. A. (2008). Using Sound Boxes Systematically to Develop Phonemic Awareness. The Reading Teacher, 62(4), 346-349. Retrieved from http://dx.doi.org/10.1598/RT.62.4.7

21. McCormick, S., \& Zutell, J. (2011). In Ramos A. (Ed.), instructing students who have literacy problems (6th Ed.). Boston, MA: Pearson.

22. Medicine Net. (2011). MedicineNet.com. Retrieved from http://www.medicinenet.com/script/main/art.asp?articlekey=152808. 23. Medina, J. (2008). Brain rules (1st ed.). Seattle, WA: Pear Press.

24. Miller, A. C., \& Keenan, J. M. (2009). How word decoding skill impacts text memory: The centrality deficit and how domain knowledge can compensate. Annals of Dyslexia, 59(2), 99-113. Retrieved from http://dx.doi.org/10.1007/s11881-009-0025-x

25. Phillips, B., \& Torgesen, J. (2006). Phonemic awareness and reading: Beyond the growth of initial reading accuracy. Handbook of early literacy research, 2, 101-113. 
26. Phipps, B. (2011). A Study of Phonics Instruction: Teaching Phonics Dance to At-Risk Elementary Students to Improve Decoding Skills: Centennial Library.

27. Phipps, B. (2011). A Study of Phonics Instruction: Teaching Phonics Dance to At-Risk Elementary Students to Improve Decoding Skills: Centennial Library.

28. Pinto, G., Bigozzi, L., Tarchi, C., Accorti Gamannossi, B., \& Canneti, L. (2015). Cross-lag analysis of longitudinal associations between primary school students' writing and reading skills. Read Writ, 28(8),1233-1255. Retrieved from http://dx.doi.org/10.1007/s11145-0159569-9

29. Ratey, J., M. D. (2008). Spark (1st ed.). New York, NY: Little, Brown \& Company.

30. Schneider, E. \& Crombie, M. (2008). Dyslexia and Foreign Language Learning. London: David Fulton Publishers, Print.

31. Shams, L., \& Seitz, A. R. (2008). Benefits of multisensory learning. Trends in Cognitive Sciences, 12(11), 411-417.

32. Sprenger, M. (2008). Differentiation through learning styles and memory (2nd ed.).Thousand Oaks, CA: Corwin Press.

33. The New Zealand Tertiary Education.(2017).The National Centre of Literacy and Numeracy for Adults. Retrieved from http://www.literacyandnumeracyforadults.com/resources/355013

34. Ukrainetz, T. A. (2009). Phonemic Awareness. Topics in Language Disorders, 29(4), 344-359. Retrieved from http://dx.doi.org/10.1097/TLD.0b013e3181c29d9e

35. Zeece, P. D. (2006). Sound Reading and Reading Sounds: The Case for Phonemic Awareness. Early Childhood Education Journal, 34(2), 169-175. Retrieved from http://dx.doi.org/10.1007/s10643-006-0125-8

36. Zelinkova, O. (2009). Foreign Languages and specific learning disabilities (1st ed). Brod Tobias year $167 \mathrm{~s}$, ISBN 80-7311-022-9.

37. Zimmerman, B. S., Padak, N., \& Rasinski, T. V. (2008). Evidencebased instruction in reading: A professional development guide to Phonics. Boston: A \& B/Pearson. 